\title{
Investigating efficiency improvement in sulfur recovery unit using process simulation and numerical modeling
}

\author{
Farhad Fazlollahi1 ${ }^{1, a,{ }^{*}}$ Sajjad Asadizadeh ${ }^{2, a}$, Milad Ahmadi Khoshooei ${ }^{3, a}$, Mohammad Reza Sardashti Birjandi ${ }^{4}$, \\ and Majid Sarkari ${ }^{2}$

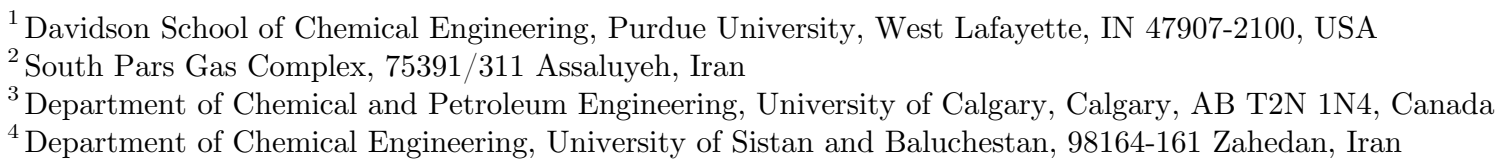

Received: 23 January 2020 / Accepted: 1 December 2020

\begin{abstract}
Hydrogen sulfide exists mostly as a detrimental byproduct in the gas processing units as well as refineries, and it must be eliminated from natural gas streams. In a Sulfur Recovery Unit (SRU), hydrogen sulfide is converted into the elemental sulfur during the modified Claus process. Efficiency of sulfur recovery units significantly depends on the reaction furnace temperature. In this work, the effect of oxygen and acid gas enrichment on the reaction furnace temperature and accordingly on sulfur recovery is studied, using both numerical modeling and process simulation. Then, simulation and numerical model are benchmarked against the experimental data of an SRU unit. The validated model provides spotlight on optimizing the upstream sulfur removal unit as well as the oxygen purification process. Two cases of acid gas streams with low and high $\mathrm{H}_{2} \mathrm{~S}$ content, $30 \%$ and $50 \%$, are studied to investigate the effect of operating parameters on the overall recovery. Finally, average errors of the models are presented. According to the absolute difference with experimental values, the developed numerical model shows great potential for accurately estimating overall efficiency of the recovery unit.
\end{abstract}

\section{Introduction}

Hydrogen sulfide exists as an impurity in natural gas reserves and therefore appears as a harmful byproduct in the gas processing units as well as desulfurization units in refineries. Due to its high toxicity, it must neither be vented to atmosphere, nor incinerated which leads to production of sulfur oxides that potentially endanger the surrounding ecosystem. Moreover, deposition of sulfur in the pipelines and gas metering systems could potentially cause serious issues to the operation, leading to low production and/or unfavorable shutdowns [1]. Not to mention, the corrosive nature of hydrogen sulfide mandates the use of specialty materials, which leads to substantial increase in the capital costs [1]. Furthermore, the deposition of solid sulfur in the measuring instruments can lead to a measurement error of $2 \%$ that in return considerably influences the production flow rates and revenues as a result [2]. Therefore, efficient removal of hydrogen sulfide from natural gas and flue gas streams is essential. Many different approaches have been

\footnotetext{
a Equal contribution.

* Corresponding author: ffarhad@alumni.purdue.edu;

farhad.fazlollahi@gmail.com
}

attempted to eliminate this toxic compound from gas streams. Absorption and adsorption methods are of the most globally recognized methods that are used to sweeten different gas streams. Membranes are also getting great worldwide attraction to be commercially used for sulfur removal. The advantage of effectively designed membranes is that they can potentially convert $\mathrm{H}_{2} \mathrm{~S}$ into elemental sulfur and hydrogen and then selectively separate and purify produced hydrogen [3]. Dos Santos et al. conducted a literature review on main methods for removing components containing sulfur in gas streams [1]. Biological processes are also another attractive pathway for removing this toxic component from various gas streams [4], which may not be practical for oil and gas industry.

However, due to stringent environmental constraints, after the removal of $\mathrm{H}_{2} \mathrm{~S}$ from fossil fuels, it should not be released to atmosphere. As a result, many approaches have been tried to convert $\mathrm{H}_{2} \mathrm{~S}$ to sulfur and hydrogen [5], out of which the Claus process has been well stablished and is widely practiced worldwide. As well, the injection of acid gas streams which are rich is hydrogen sulfide is also proposed to avoid the release of this harmful component into atmosphere. However, this method is potentially challenging due to the toxic and corrosive nature of $\mathrm{H}_{2} \mathrm{~S}$ [6]. Yet, 
preliminary economic analysis has shown reduced capital costs for the case of acid gas injection, as compared to the Claus process [7]. However, currently converting hydrogen sulfide is more stablished and well-practiced, owing to it maturity and high efficiency. Sulfur Recovery Units (SRU) produce elemental sulfur by converting hydrogen sulfide [8]. In addition, it is possible to produce hydrogen from $\mathrm{H}_{2} \mathrm{~S}$ conversion, which adds further merits to the process, from an economical point of view. However, it is challenging to decompose hydrogen sulfide to obtain hydrogen as it requires high temperature, $>1000 \mathrm{~K}$ [9]. Catalytic pathway for thermally decomposing $\mathrm{H}_{2} \mathrm{~S}$ has shown great efficiency, while providing an opportunity to recover the produced hydrogen [10]. Other methods including thermochemical process, photocatalytic approach, electrolysis, hydrolysis and reactive adsorption have also been attempted, showing great potentials for hydrogen recovery and high sulfur recovery rate, but they are all still in their infancy [9, 11-13]. Yet, the Claus process is still the leading pathway for converting hydrogen sulfide to elemental sulfur, owing to its maturity developed over several years of research and operation. It is noteworthy that the overall sulfur recovery depends on the efficiency of the tail gas treatment technique [5]. Another approach is to integrate SRU with other chemical processes for enhancing the recovery rate as well a hydrogen production. Recently, Damanabi and Bahadori [14] proposed a new approach to integrate hydrocarbon reforming and the Claus process to obtain hydrogen from the process, while reducing the tail gas flow rate.

The Claus process was modified, and the modified process is currently widely practiced for conversion of hydrogen sulfide to the elemental sulfur. As stated by ZareNezhad [15] and Signor et al. [16], the requirements of the Claus units are dictated by the operating conditions of modern natural gas refineries and increasingly stringent emission control regulations. The process modifications have allowed handling a wide range of acid gas compositions [17].

\subsection{Process description}

It is well stablished that the overall reaction of modified Claus process is divided into two sections: (a) a highly exothermic thermal or combustion reaction in reaction furnace and (b) an exothermic catalytic reaction, equipped with waste heat boilers, convertors and condensers where the produced sulfur dioxide in the combustion section reacts with the unburnt $\mathrm{H}_{2} \mathrm{~S}$ to generate the elemental sulfur [16]. ZareNezhad and Hosseinpour [18] described that acid gas and combustion air receive a reaction furnace operating at about $1000{ }^{\circ} \mathrm{C}$ to reach about $50 \%$ conversion to elemental sulfur and also to generate an $\mathrm{H}_{2} \mathrm{~S} / \mathrm{SO}_{2}$ molar ratio of $2: 1$. Different reactions occur in the reaction furnace that can be classified in three principal reactions:

1. One-third of the hydrogen sulfide in the acid gas stream is oxidized to $\mathrm{SO}_{2}$, in the presence of air. This reaction is highly exothermic and increases the temperature of reaction furnace and flame stability:

$$
\mathrm{H}_{2} \mathrm{~S}+3 / 2 \mathrm{O}_{2} \leftrightarrow \mathrm{SO}_{2}+\mathrm{H}_{2} \mathrm{O} .
$$

2. A fraction of $\mathrm{SO}_{2}$ produced in the reaction furnace, reacts with the unburnt $\mathrm{H}_{2} \mathrm{~S}$ to form the elemental sulfur. This reaction is endothermic; therefore, decreasing the temperature leads to greater sulfur yield. This endothermic reaction is accounted for production of two-third of the total sulfur production in the SRU unit:

$$
2 \mathrm{H}_{2} \mathrm{~S}+\mathrm{SO}_{2} \leftrightarrow 3 / 2 \mathrm{~S}_{2}+2 \mathrm{H}_{2} \mathrm{O} .
$$

3. The combustion of some hydrocarbons, $\mathrm{CO}_{2}$ and other flammable impurities present in the acid gas stream also occurs. As a result, Carbon DiSulfide $\left(\mathrm{CS}_{2}\right)$, CarbOnyl Sulfide (COS), and Carbon monOxide (CO) are also produced in the furnace.

The above is a basic explanation of the reactions essentially taking place in the reaction furnace. Due to $\mathrm{H}_{2} \mathrm{~S}$ and $\mathrm{SO}_{2}$ reaction in the ratio of $2: 1$, it is advantageous to oxidize only one-third of the intake $\mathrm{H}_{2} \mathrm{~S}$. El-Bishtawi and Haimour [8] and Boussetta et al. [19] express that the Waste Heat Boiler (WHB) is placed after the reaction furnace so that the heat from product gases in reaction furnace can be recovered and used to generate steam. The equilibrium reaction is convoluted by the existence of different species, whose equilibrium concentrations in relation to each other are not exactly known for the total range of process conditions. As stated, other impurities are also produced, which are proven to produce $20-50 \%$ of the tail-gas pollutants $[13,20]$. For instance, Chardonneaua et al. [21] showed that $1-3 \%$ of toluene as impurity leads to a $50 \%$ reduction in conversion efficiency of hydrogen sulfide in the Claus process. However, toluene appears to be destructed in the thermal stage, if enriched flow of oxygen is used [22]. Therefore, it is quite challenging to accurately estimate the furnace flame temperature and gas product composition.

Furthermore, many approaches have been attempted to enhance the overall efficiency of the Claus process, with specific focus on increasing reaction furnace temperature [18] and improving catalytic activity [15], both of which lead towards increased $\mathrm{H}_{2} \mathrm{~S}$ conversion. It is worth noting than furnace temperature is recommended to be at least $1050{ }^{\circ} \mathrm{C}$ to ensure high conversion of hydrogen sulfide as well as decomposition of hydrocarbons. A common industrial practice is co-firing of the acid gas with natural gas for increasing the furnace temperature. However, due to the increased hydrocarbon concentration in the inlet feed, the possibility of producing $\mathrm{CS}_{2}$ also adversely increases. In addition, it is shown that in the case of co-firing with natural gas, the temperature increase does not exceed the desired threshold of $1050{ }^{\circ} \mathrm{C}$, even for acid gas streams with $40 \% \mathrm{H}_{2} \mathrm{~S}$ [15]. Preheating of the air and acid gas also enhances the temperature of the reaction furnace, but in return increases the capital and operational costs. The most effective approach for improving the efficiency of the Claus process is enriching the air stream in oxygen and the acid gas stream in hydrogen sulfide. This approach not only reduces the operational costs, but also reduces the capital costs as less impurity assures smaller process equipment, piping, and instrumentations. Not to mention, enriched 
acid gas streams should be free of water as in the presence of water, hydrogen sulfide reacts with iron in the construction material and promotes cracking the infrastructure [18]. Ibrahim et al. [23] showed that the presence of water not only worsens the thermal efficiency in the reaction furnace, but also promotes the production of unwanted aromatic hydrocarbons.

Many gas refineries employ oxygen enriched air streams in sulfur recovery units. In some cases, oxygen enrichment is used to improve the throughput capacity of the gas refinery. However, in most specific cases, oxygen enrichment is used to increase temperature and sulfur recovery of reaction furnace. As well, efficient control of mixing of combustion gases is important in order to prevent oxygen breakthrough into the catalytic converters. The poor uniformity in the combusting gases leads to unreacted oxygen remaining in the gas to further oxidize $\mathrm{SO}_{2}-\mathrm{SO}_{3}$ before the gas stream arrived the catalyst bed. Then, this $\mathrm{SO}_{3}$ reacts with the catalysts of converters and deactivates them by producing aluminum sulfate. Also, Craig and Anderson [24] described that $\mathrm{SO}_{3}$ can react with $\mathrm{H}_{2} \mathrm{O}$ to constitute sulfuric acid, which is a corrosion composition for damaging downstream steel facilities depending on different variables such as temperature and concentration of acid. Furthermore, oxygen enrichment is found to enhance the destruction of benzene, toluene [22] and polyaromatic compound [25] that may present in the acid gas stream. However, it is also noteworthy that depending on the composition of acid gas, significantly increased reaction furnace temperatures might adversely increase the production of COS after WHB and therefore in the overall SRU process [26]. Therefore, careful simulation and modeling of SRU units is urged to assess the impact of reaction furnace temperature on the overall SRU efficiency.

In this article, we present a Claus process simulation as well as numerical modeling for evaluation of air and acid gas enrichment that potentially affects the reaction furnace temperature and $\mathrm{H}_{2} \mathrm{~S}$ conversion efficiency in sulfur recovery unit that process both low and high hydrogen sulfide contents. For the first time, both process simulation and numerical modeling approach are employed to assess the effect of oxygen enrichment and acid gas enrichment on the thermal stage of the overall SRU unit. A detailed effect of enhanced reaction furnace temperature is discussed and the potential impact on the sulfur recovery is remarked and actual field data are benchmarked against process simulation and numerical modeling. A case study of an SRU in the South Pars Gas Complex, Iran, is also presented to validate the proposed simulation and numerical modeling. The predicted results of simulation and numerical modeling are benchmarked against the experimental data from the refinery plant. The effectiveness of commercially viable methods used for increasing the temperature and sulfur recovery of Claus reaction furnace are represented by the proposed approaches.

\section{Methodology}

In this work, the effect of different concentrations of oxygen in air, as well as $\mathrm{H}_{2} \mathrm{~S}$ concentration in acid gas on the reaction furnace temperature and ultimately sulfur recovery is evaluated, using process simulation as well as numerical modeling. Figure 1 represents the Claus process flow diagram of a sulfur recovery unit. In this process, the acid gas stream enters the SRU and is split into two streams in the acid gas splitter. One stream introduces to the main burner and the other stream enters the acid gas heater for hydrolyzing sulfur components to $\mathrm{H}_{2} \mathrm{~S}$. It is shown that the split ratio should be optimum, in order to obtain the optimum reaction temperature in the reaction furnace [27]. The desired acid gas flow ratio in the acid gas splitter assures high enough temperature in the furnace, while keeping the reaction stoichiometry in such a way that the sulfur recovery enhances and the production of $\mathrm{COS}$ and $\mathrm{CS}_{2}$ reduces.

El-Bishtawi and Haimour [8] and Boussetta et al. [19] presented that the outlet gas from the main burner passes through the first pass of the waste heat boiler, where the generated heat is removed from the hot gas by generating high pressure steam at 40 Barg on the shell side. ZareNezhad and Hosseinpour [18] showed that the redistribution of $\mathrm{S}_{2}-\mathrm{S}_{8}$ as a primary reaction is taking place in the second pass of the WHB. In addition, some byproducts such as COS and $\mathrm{CS}_{2}$ are produced in this part. The outlet stream from the second pass WHB is condensed in the thermal condenser to recover elemental sulfur in the liquid form. The outlet gas from thermal condenser is then preheated in the first reheater and is sent to the three catalytic converters where the Claus reactions take place at lower temperatures.

ZareNezhad [15] showed that since the first catalytic converter typically works at high enough temperature, therefore $\mathrm{COS}$ and $\mathrm{CS}_{2}$ is hydrolyzed in the first catalytic converter according to the exothermic reactions in equations (3) and (4):

$$
\begin{gathered}
\mathrm{COS}+\mathrm{H}_{2} \mathrm{O} \leftrightarrow \mathrm{CO}_{2}+\mathrm{H}_{2} \mathrm{~S}, \\
\mathrm{CS}_{2}+2 \mathrm{H}_{2} \mathrm{O} \leftrightarrow \mathrm{CO}_{2}+2 \mathrm{H}_{2} \mathrm{~S} .
\end{gathered}
$$

Zagoruiko and Matros [28] indicated that $\gamma-\mathrm{Al}_{2} \mathrm{O}_{3}$ or $\mathrm{TiO}_{2}$ catalysts are usually employed for this process. Clarke et al. [29] presented that in industry sulfate is produced, when $\mathrm{H}_{2} \mathrm{~S}$ and $\mathrm{SO}_{2}$ mixtures are passed on the $\gamma-\mathrm{Al}_{2} \mathrm{O}_{3}$ catalyst.

After each catalytic convertor, sulfur is produced by cooling the effluent gas in a sulfur condenser. Finally, the effluent gas from the process is sent to the tail gas incinerator, where any remaining sulfur compounds are converted to $\mathrm{SO}_{2}$ and discharged through the stack to the atmosphere. In this study, the sulfur recovery unit simulation is carried out using PROMAX process simulator, version 3.2. PROMAX is a widely used process simulator for gas processing units and well-recognized in the capability of simulating sulfur recovery processes. Mattsson-Bose and Lyddon [30] expressed that this simulator will assume that the Claus beds activate at $95 \%$ of equilibrium conversion and 4(lb) sulfur/100 moles of gas are flowed in the sulfur condensers. Lins and Guimaraes [17] as well as Mattsson-Bose and Lyddon [30] showed that burner and waste heat boiler are simulated by the use of main burner, first pass WHB 


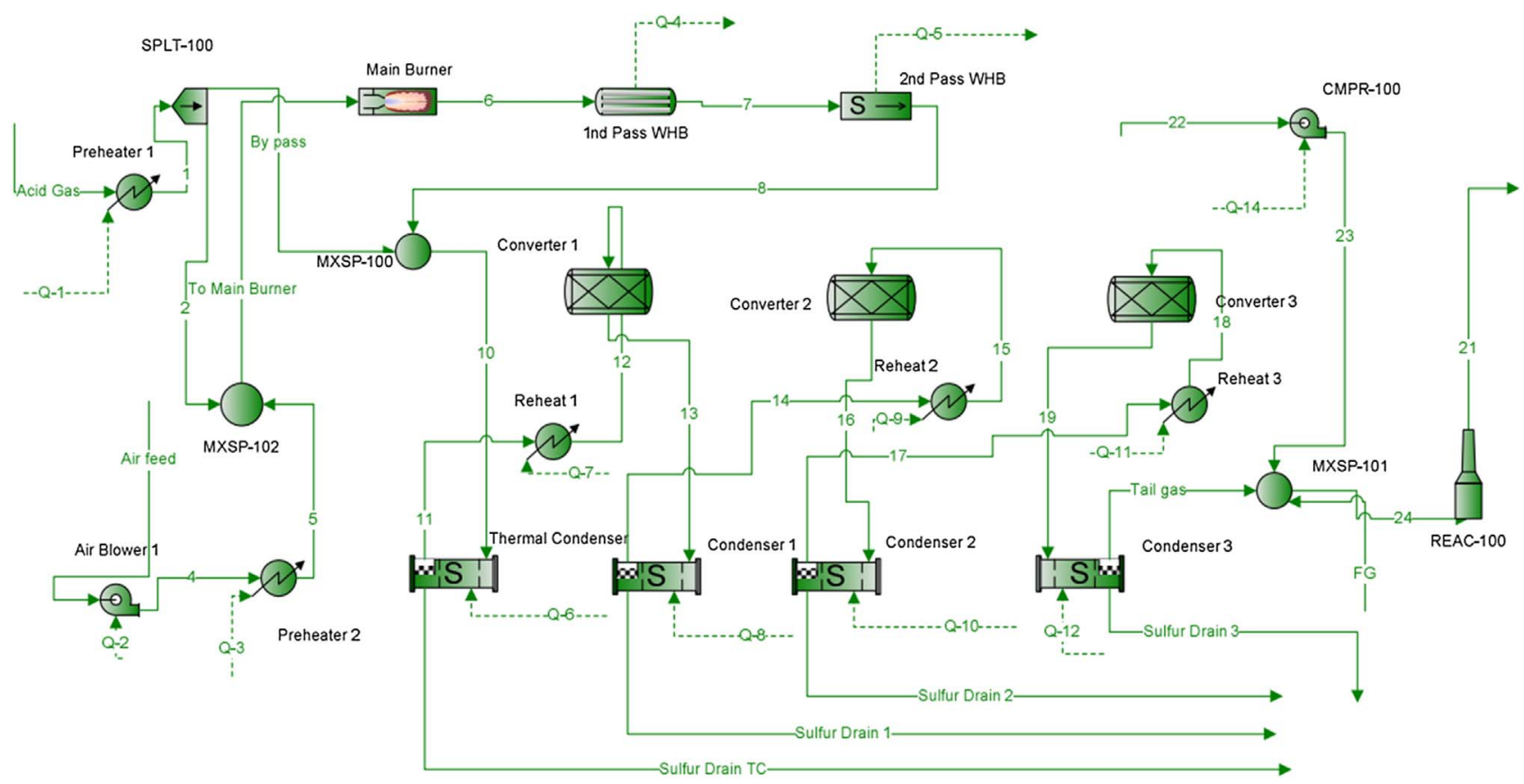

Fig. 1. Schematic process flow diagram of sulfur recovery unit using Claus process.

and second pass WHB. Acid gas combustion with COS is simulated by burner and formation of $\mathrm{CS}_{2}$ is calculated by NSERC 1993 correlation [31]. This correlation estimates $\mathrm{COS}, \mathrm{CS}_{2}, \mathrm{CO}, \mathrm{H}_{2}$, and/or $\mathrm{S}_{2}$ concentrations in the burner outlet.

Table 1 shows the normal operating conditions and composition of the acid gas stream to the actual field SRU unit in South Pars Gas Complex.

\section{Numerical modeling}

The model is adapted from [18] to numerically model the experimental data. Details of specific equations are provided in the Supporting Information, Equations (S1)-(S10) [18]. To start the problem solution, at first it is essential to specify the components likely to be present in significant amount at equilibrium. Since in the gas sweetening units, $\mathrm{H}_{2} \mathrm{~S}, \mathrm{CO}_{2}, \mathrm{H}_{2} \mathrm{O}$ and light hydrocarbon usually exist in the produced acid gas, the mixture of reaction is assumed here to contain 10 components, $\mathrm{H}_{2} \mathrm{~S}, \mathrm{CO}_{2}, \mathrm{CO}, \mathrm{CS}_{2}$, COS, $\mathrm{SO}_{2}, \mathrm{~S}_{2}, \mathrm{H}_{2}, \mathrm{~N}_{2}$ and $\mathrm{H}_{2} \mathrm{O}$, as per the industrial data. Table 2 summarizes the thermochemical properties of these components, obtained from NIST Thermochemical Table.

The solution algorithm, which is obtained from minimum value of Gibbs free energy summarizes as follows:

1. Enter the initial guess for acid gas temperature $\left(T=800{ }^{\circ} \mathrm{C}\right)$.

2. Guess the injection air flow rate (by changing $b_{i}$ value).

3. Compute the $\mu_{j}$ value from Equation (S5).
Table 1. Normal operating conditions and composition of the acid gas stream.

\begin{tabular}{lc}
\hline Pressure $($ barg $)$ & 1.7 \\
Temperature $\left({ }^{\circ} \mathrm{C}\right)$ & 45 \\
Molar flow rate $\left(\mathrm{kmol} \mathrm{h}^{-1}\right)$ & \\
$\mathrm{CO}_{2}$ & 230.2 \\
$\mathrm{H}_{2} \mathrm{~S}$ & 147.8 \\
Methane & 2.2 \\
Ethane & 0.2 \\
Benzene & 0.1 \\
Toluene & $<0.1(0.01)$ \\
$\mathrm{H}_{2} \mathrm{O}$ & 19.2 \\
\hline
\end{tabular}

Then, solve the matrix format of Equations (S8)-(S10) to obtain the correction factors using initial estimates of $N_{j}$ and apply the obtained correction variables to obtain the enhanced values of $N_{j}$ and $N$ according to equations (5) and (6):

$$
\begin{gathered}
\left(\ln N_{j}\right)_{\text {new }}=\left(\ln N_{j}\right)_{\text {old }}+\Delta\left(\ln N_{j}\right), \\
(\ln N)_{\text {new }}=(\ln N)_{\text {old }}+\Delta(\ln N) .
\end{gathered}
$$

4. If the $N_{\mathrm{H}_{2} \mathrm{~S}} N_{\mathrm{SO}_{2}}$ is not equal to 2 , a new injection air rate is assumed, and calculation is reiterated from step 3. 
Table 2. Enthalpy and Gibbs free energy of formation and heat capacity parameters ${ }^{\mathrm{a}, \mathrm{b}}$ of pure components.

\begin{tabular}{lccrrrrr}
\hline Component & $\Delta H_{f}^{\circ}\left(\mathrm{kJ} \mathrm{mol}^{-1}\right)$ & $\Delta G_{f}^{\circ}\left(\mathrm{kJ} \mathrm{mol}^{-1}\right)$ & $A$ & $B \times 10^{3}$ & $C \times 10^{6}$ & $D \times 10^{9}$ & $E \times 10^{-6}$ \\
\hline $\mathrm{H}_{2} \mathrm{~S}$ & -20.502 & -33.329 & 26.8841 & 18.6780 & 3.4342 & -3.3787 & 0.1359 \\
$\mathrm{CO}_{2}$ & -393.522 & -394.389 & 24.9974 & 55.1870 & -33.6910 & 7.9484 & -0.1366 \\
$\mathrm{CO}$ & -110.527 & -137.163 & 25.5676 & 6.0961 & 4.05470 & -2.6713 & 0.1310 \\
$\mathrm{CS}_{2}$ & 116.943 & 66.816 & 35.8539 & 52.4912 & -40.8370 & 12.0016 & -0.2248 \\
$\mathrm{COS}$ & -138.407 & -165.601 & 34.5389 & 43.0538 & -26.6180 & 6.3388 & -0.3275 \\
$\mathrm{SO}_{2}$ & -296.842 & -300.125 & 21.4305 & 74.3509 & -57.7520 & 16.3553 & 0.0867 \\
$\mathrm{~S}_{2}$ & 128.6 & 79.687 & 33.5131 & 5.0654 & -1.0597 & 0.08991 & -0.2119 \\
$\mathrm{H}_{2}$ & 0 & 0 & 33.0662 & -11.3634 & 11.4328 & -2.7729 & -0.1586 \\
$\mathrm{~N}_{2}$ & 0 & 0 & 28.9864 & 1.8540 & -9.6475 & 16.6354 & 0.0001 \\
$\mathrm{H}_{2} \mathrm{O}$ & -241.826 & -228.582 & 30.0920 & 6.8325 & 6.7934 & -2.5345 & 0.0821 \\
\hline
\end{tabular}

${ }^{\mathrm{a}} C_{p}=A+B \times T+C \times T^{2}+D \times T^{3}+E \times T^{-2}$.

${ }^{\mathrm{b}}$ Parameters in this table are for certain temperature range, for full range NIST website to be consulted.

5. If the $N_{\mathrm{H}_{2} \mathrm{~S}} N_{\mathrm{SO}_{2}}$ is equal to 2 , the supposed temperature should be confirmed by the following energy balance equation [18]:

$$
\sum_{R} N_{R}\left[h_{f}^{\circ}+\Delta h\right]_{R}-\sum_{P} N_{P}\left[h_{f}^{\circ}+\Delta h\right]_{j}=0
$$

where,

$$
\Delta h=\int_{298.15}^{T} C_{P}(T) \mathrm{d} T
$$

The thermodynamic properties for specific heat capacity $\left(C_{p}\right)$ can be found in Table 2 . If the initial guess of temperature does not satisfy the previous equation, a new $T$ should be assumed, and the calculations are repeated from step 1.

6. If equation (7) is satisfied, the solution of algorithm is achieved.

Figure 2 shows a flowchart that summarizes the numerical algorithm for obtaining the solution for the reaction furnace temperature and accordingly sulfur recovery in this thermal step.

\section{Results and discussion}

The effect of oxygen enrichment in increasing temperature and sulfur recovery in the reaction furnace is investigated by PROMAX process simulator as well as the proposed numerical algorithm in Figure 2 and the results are compared against experimental data obtained from a gas refinery.

The expected reaction furnace temperature is compared with plant data for the $30 \%$ and $50 \% \mathrm{H}_{2} \mathrm{~S}$ acid gas cases in Figures 3 and 4, respectively. The results show that oxygen enrichment will have an important effect on the reaction furnace temperature for acid gas streams with different

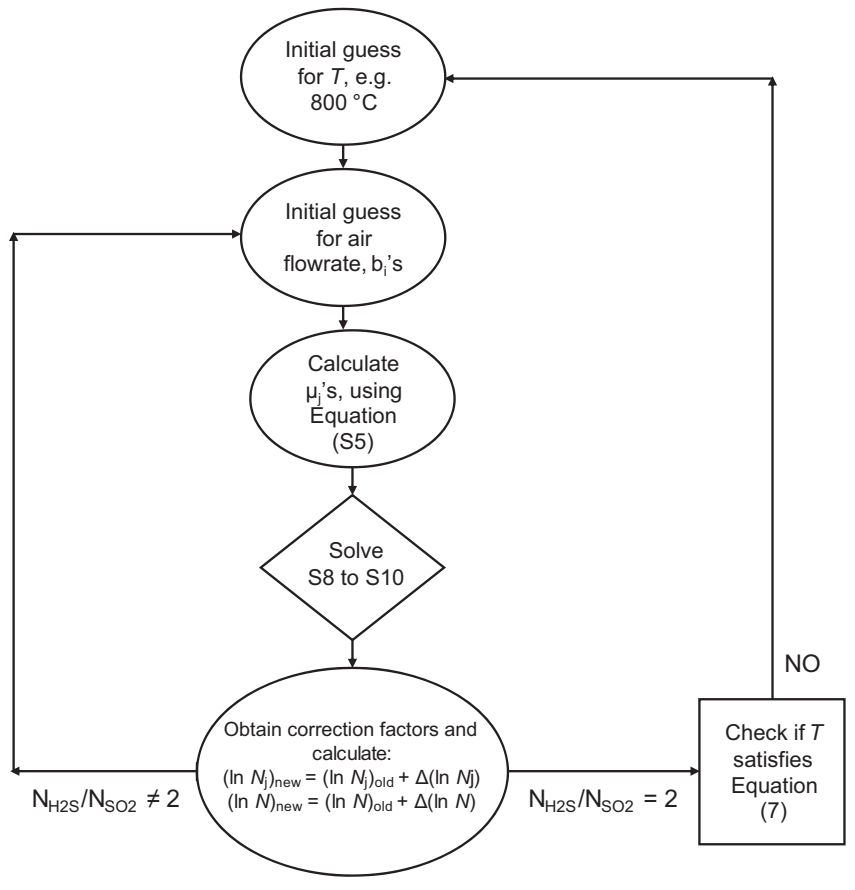

Fig. 2. Numerical algorithm for modeling of reaction furnace in sulfur recovery unit.

hydrogen sulfide contents. Also, sufficient oxygen enrichment in the air flow increases the reaction furnace temperature to above the $1450{ }^{\circ} \mathrm{C}$ in the case of $50 \% \mathrm{H}_{2} \mathrm{~S}$. As well, the results imply that the reaction furnace temperature rises between 25 and $50{ }^{\circ} \mathrm{C}$ for every increment of $10 \%$ oxygen enrichment. However, in the case of $30 \% \mathrm{H}_{2} \mathrm{~S}$ acid gas, the enrichment appears to have much less effect on the reaction furnace temperature beyond $50 \%$ oxygen enrichment. Similar behavior was observed by others [18]. Such an observation is essential in optimizing the upstream sulfur removal unit to ensure adequate enrichment of the acid gas stream. The results of numerical modeling algorithm are in good agreement with the plant data as illustrated in Figures 3 and 4. However, the process simulator seems 


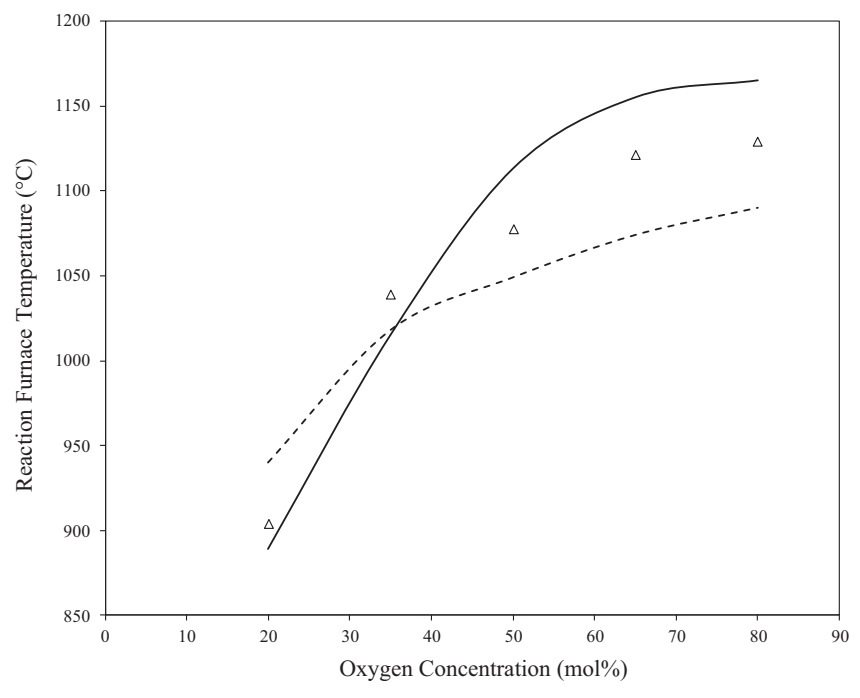

Fig. 3. Effect of oxygen enrichment on reaction furnace temperature for acid gas stream containing $30 \% \mathrm{H}_{2} \mathrm{~S}$; experimental data points are represented by triangles and solid and dash curves are developed using numerical modeling and PROMAX simulator.

to underestimate the reaction furnace temperature in the case of oxygen enrichment.

As shown in Figures 3 and 4, by increasing oxygen concentration, temperature of reaction furnace increases. In addition, higher $\mathrm{H}_{2} \mathrm{~S}$ concentration in acid gas feed increases the reaction furnace temperature. In the case of $30 \% \mathrm{H}_{2} \mathrm{~S}$ acid gas stream, according to the numerical algorithm results, the main burner temperature increases from $889^{\circ} \mathrm{C}$ in $20 \%$ oxygen concentration to $1165^{\circ} \mathrm{C}$ in $80 \%$ oxygen concentration. On the other hand, in the case of $50 \%$ $\mathrm{H}_{2} \mathrm{~S}$ acid gas, temperature of reaction furnace increased from $902{ }^{\circ} \mathrm{C}$ in $20 \%$ oxygen concentration to $1471{ }^{\circ} \mathrm{C}$ in $80 \%$ oxygen concentration. In the case of $30 \% \mathrm{H}_{2} \mathrm{~S}$, according to process simulator results, the main burner temperature increased from $941{ }^{\circ} \mathrm{C}$ in $20 \%$ oxygen concentration to $1088{ }^{\circ} \mathrm{C}$ in $80 \%$ oxygen concentration. In the case of $50 \% \mathrm{H}_{2} \mathrm{~S}$, temperature reaction furnace is changed from $1098{ }^{\circ} \mathrm{C}$ in $20 \%$ oxygen concentration to $1402{ }^{\circ} \mathrm{C}$ in $80 \%$ oxygen concentration. However, the simulated results of suggested algorithm and process simulator are in good agreement with the experimental data, where the results of the numerical method are closer to the experimental data as illustrated in Figures 3 and 4 . It is also noteworthy that for the same oxygen enrichment level, the reaction furnace temperature is higher for the case of the acid gas stream with greater $\mathrm{H}_{2} \mathrm{~S}$ content and the difference between two cases become more noticeable for further oxygen enrichment. Figure 5 highlights the effect of acid gas enrichment on the reaction furnace temperature in a sulfur recovery unit. These results provide spotlight on optimizing the upstream $\mathrm{H}_{2} \mathrm{~S}$ stripping as well as the air generation facilities. A tradeoff between the lower capital costs of $\mathrm{H}_{2} \mathrm{~S}$ removal unit and operational costs of air generation unit is to be made. The synergy between oxygen enrichment and acid gas enrichment is also essential to assure the

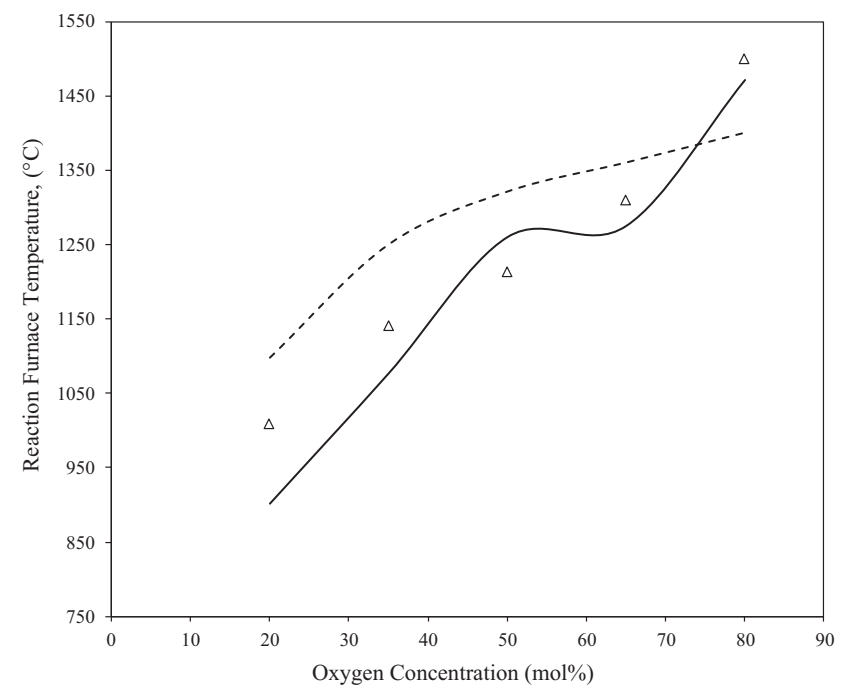

Fig. 4. Effect of oxygen enrichment on reaction furnace temperature for acid gas stream containing $50 \% \mathrm{H}_{2} \mathrm{~S}$; experimental data points are represented by triangles and solid and dash curves are developed using numerical modeling and PROMAX simulator.

minimum reaction furnace temperature of $1050{ }^{\circ} \mathrm{C}$. The developed model assures that the optimal oxygen enrichment can be estimated for any acid gas stream, with any given composition, provided that the algorithm in Figure 2 is followed.

In the next section, the effect of oxygen concentration on sulfur recovery in the reaction furnace is investigated. Optimum reaction furnace temperature is a temperature in which more sulfur recovery is obtained in the reaction furnace. Therefore, in this section sulfur recovery of reaction furnace is studied with respect to the oxygen concentration in air stream in the Claus process. Figures 6 and 7 represent the sulfur recovery in the reaction furnace for cases of acid gas containing $30 \%$ and $50 \% \mathrm{H}_{2} \mathrm{~S}$, respectively.

As presented in Figures 6 and 7, in the case of $30 \% \mathrm{H}_{2} \mathrm{~S}$, based on presented algorithm results, optimal sulfur recovery of reaction furnace is obtained $36 \%$ in $20 \%$ oxygen concentration and then decreases as the oxygen concentration increases. Also, minimum sulfur recovery is achieved in $65 \%$ oxygen concentration. In the case of $50 \% \mathrm{H}_{2} \mathrm{~S}$, maximum sulfur recovery of reaction furnace is attained as $37.6 \%$ in $20 \%$ oxygen concentration and then reduces with respect to the oxygen concentration increase. Similar behavior was observed for the case of oxygen enrichment [18, 32]. This shows that even though acid gas enrichment increases the reaction furnace temperature, it does not necessarily enhance the sulfur recovery in this stage. Therefore, it is important to assess the kinetics and stoichiometric of reactions, not only for hydrogen sulfide but also for other acid gas constituents that could potentially impact the sulfur recovery. As stated by Bohme and Sames [33], the overall efficiency of an SRU unit is principally governed by optimum control of the stoichiometrics in several steps of the process for different acid gas streams with various compositions. 


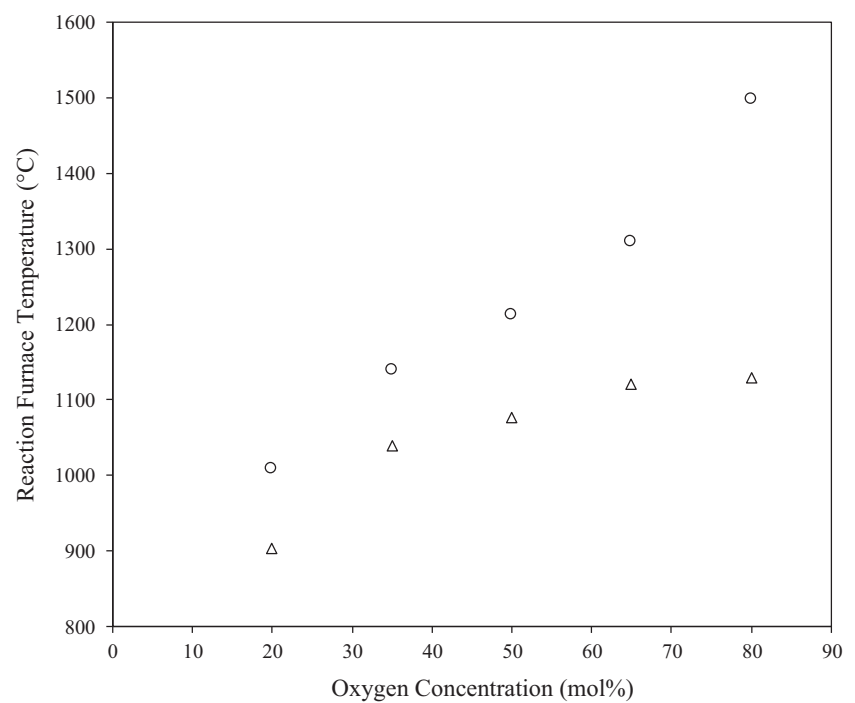

Fig. 5. Effect of acid gas enrichment on reaction furnace temperature for acid gas stream containing $30 \% \mathrm{H}_{2} \mathrm{~S}$ (triangles) and $50 \% \mathrm{H}_{2} \mathrm{~S}$ (circles).

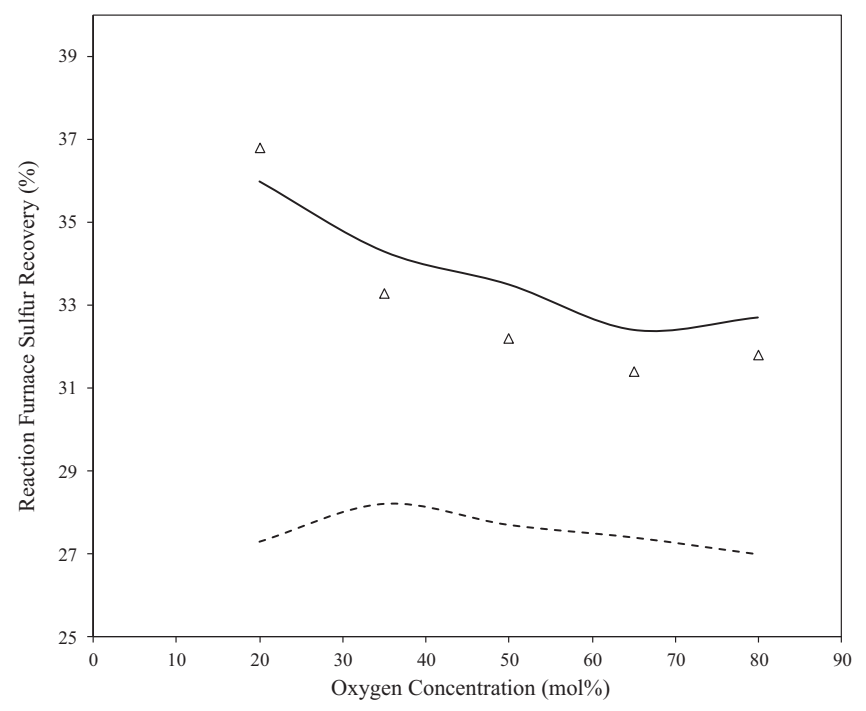

Fig. 6. Effect of oxygen enrichment on sulfur recovery in reaction furnace for acid gas stream containing $30 \% \quad \mathrm{H}_{2} \mathrm{~S}$; experimental data points are represented by triangles and solid and dash curves are developed using numerical modeling and PROMAX simulator.

According to the process simulation results, in the case of $30 \% \mathrm{H}_{2} \mathrm{~S}$ enhanced sulfur recovery of reaction furnace is estimated as $28.2 \%$ in $35 \%$ oxygen concentration and then declines with respect to the oxygen concentration. In the case of $50 \% \mathrm{H}_{2} \mathrm{~S}$, maximum sulfur recovery of reaction furnace is achieved as $31.2 \%$ in $35 \%$ oxygen concentration and then reduces with respect to the oxygen concentration. It is noteworthy that the predicted results of suggested algorithm are in close agreement with the experimental data, whereas the simulation results appear to widely

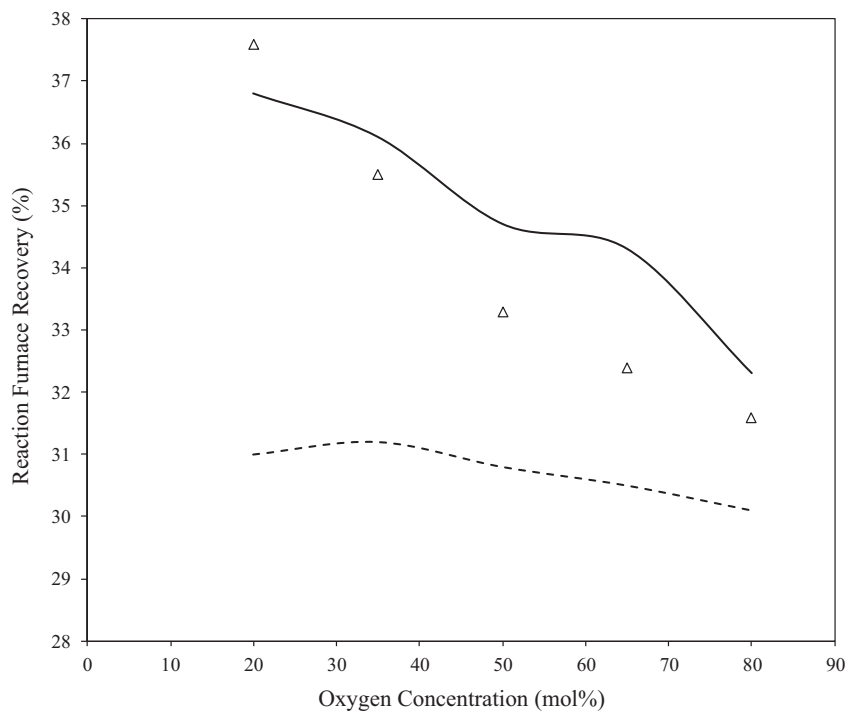

Fig. 7. Effect of oxygen enrichment on sulfur recovery in reaction furnace for acid gas stream containing $50 \% \quad \mathrm{H}_{2} \mathrm{~S}$; experimental data points are represented by triangles and solid and dash curves are developed using numerical modeling and PROMAX simulator.

underestimate the sulfur recovery in the reaction furnace for the cases of enriched oxygen streams.

In order to assess how far the estimation of the process simulator from the numerical are modeling, the difference was calculated for given oxygen and hydrogen sulfide concentrations. Figures 8 and 9 show the difference in reaction furnace temperature and sulfur recovery between two approaches. In the case of $30 \%$ acid gas, the difference in temperature is almost constant for all oxygen concentrations, except for the case of $35 \%$ oxygen enrichment, which the difference approaches to zero. Therefore, it is fair to conclude that for low acid gas concentrations, the process simulator and numerical model estimate similar results, which are in good agreement with experimental data. However, for the case of $50 \%$ acid gas stream, the difference in temperature is maximum at low oxygen concentrations and then decreases as the oxygen concentration increases until the difference reaches a minimum at $50 \%$ of oxygen enrichment and then remains almost constant, $\pm<1 \%$. As a result, one infers that for enriched acid gas stream, the developed model is superior to the process simulator for estimating the reaction furnace temperature. Figure 8 highlights these trends.

In order to further assess the validity of the numerical algorithm, the same procedure mentioned above was employed to monitor the difference in sulfur recovery in the reaction furnace. In the case of $30 \%$ acid gas, the minimum difference occurs at $50 \%$ oxygen enrichment, whereas for the $50 \%$ acid gas, the minimum difference occurs at $80 \%$ of oxygen enrichment, while there is a general decreasing trend in the difference when the oxygen concentration increases. Figure 9 illustrates the difference in sulfur recovery in the reaction furnace between the process simulator and numerical algorithm. Consequently, the numerical model shows to predict both the reaction furnace temperature 


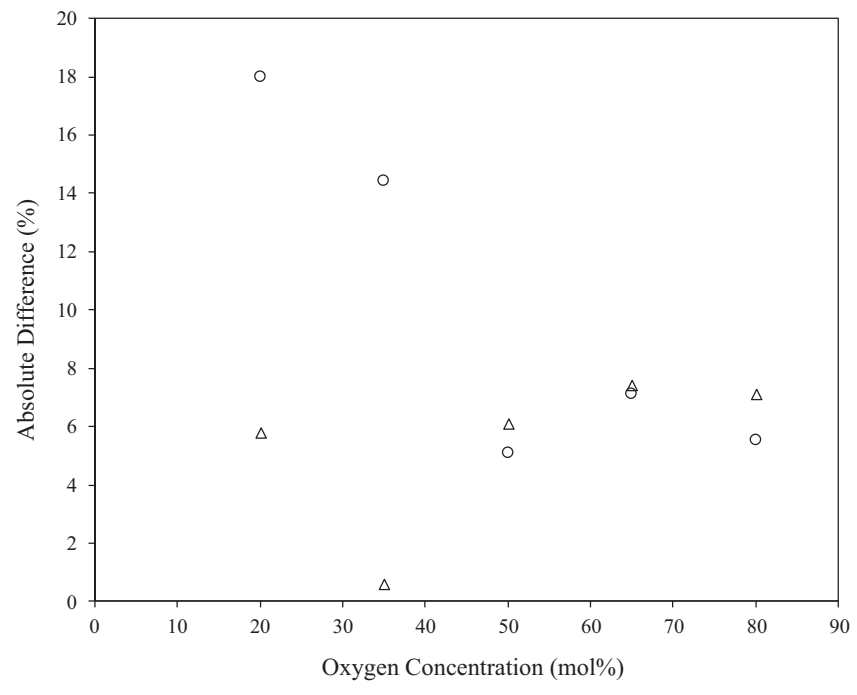

Fig. 8. Error estimation of the reaction furnace temperature based on results of model with respect to process simulator for $30 \% \mathrm{H}_{2} \mathrm{~S}$ (triangles) and $50 \% \mathrm{H}_{2} \mathrm{~S}$ (circles) acid gas streams.

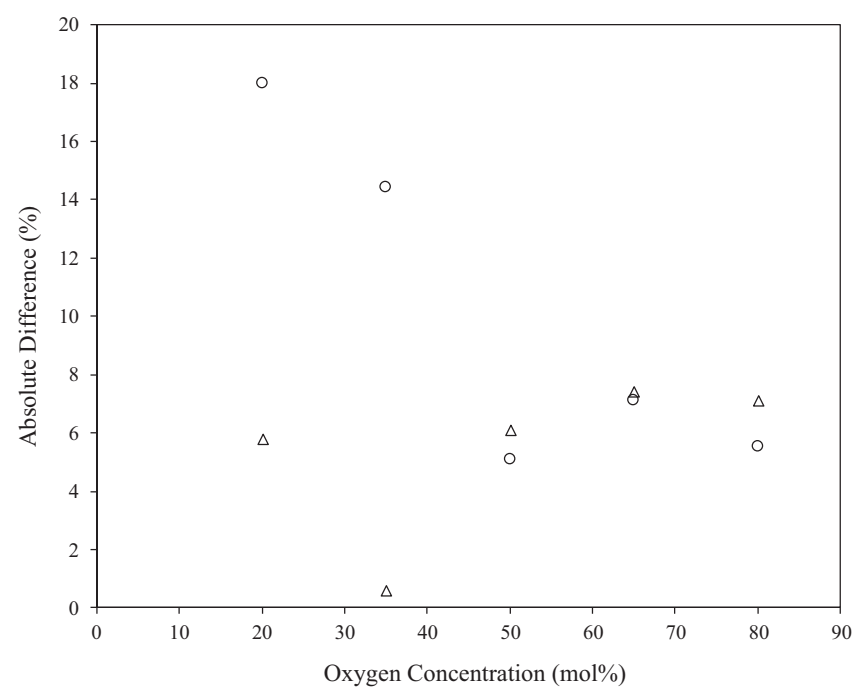

Fig. 9. Error estimation of the sulfur recovery in reaction furnace based on results of model with respect to process simulator for $30 \% \mathrm{H}_{2} \mathrm{~S}$ (triangles) and $50 \% \mathrm{H}_{2} \mathrm{~S}$ (circles) acid gas streams.

as well as the sulfur recovery in the reaction furnace accurately, especially for enriched acid gas streams, with oxygen concentrations in the range of $50-80 \%$.

\section{Conclusion}

The reaction furnace temperature as well as the sulfur recovery in the reaction furnace were evaluated, using process simulation and numerical model. Experimental data from a sulfur recovery unit in Iran was used to assess the accuracy and validity of the simulation and modeling approaches. Two cases of low and high concentrations of hydrogen sulfide in the acid gas stream, i.e. $30 \%$ and $50 \%$, were employed to study the effect of oxygen enrichment and acid gas enrichment on the reaction furnace. In the case of $30 \% \mathrm{H}_{2} \mathrm{~S}$ acid gas stream, oxygen enrichment increased the reaction furnace temperature to above $1050{ }^{\circ} \mathrm{C}$, which is the optimal temperature for the reaction furnace. However, beyond $50 \%$ of oxygen enrichment, no further significant increase in the temperature was observed. Furthermore, the sulfur recovery in the reaction furnace decreased as the oxygen concentration increased. Therefore, $50 \%$ of oxygen enrichment seems to be the optimal case for processing lean acid gas streams. As enriching oxygen increases the operational costs of the sulfur recovery plant, it is therefore not economical to further increase the oxygen concentration for the cases of low concentrations of hydrogen sulfide in acid gas streams.

In the case of rich acid gas, $50 \% \mathrm{H}_{2} \mathrm{~S}$, the reaction furnace temperature increased sharply as the oxygen concentration increased. On the contrary, the sulfur recovery in the reaction furnace decreased as the oxygen concentration increased. Therefore, it is conclusive to state that for rich acid gas streams, the optimal oxygen enrichment is in the range of $35-50 \%$. As well, the effect of oxygen enrichment on rich acid gas streams was more considerable.

The numerical model showed great accuracy in predicting the reaction furnace temperature in both cases. The results were in good agreement with the experimental data. However, the process simulation seems to underestimate the reaction furnace temperature as well as the sulfur recovery in the reaction furnace.

\section{References}

1 dos Santos J.P.L., de Carvalho Lima Lobato A.K., Moraes C., de Lima Cunha A., da Silva G.F., dos Santos L.C.L. (2016) Comparison of different processes for preventing deposition of elemental sulfur in natural gas pipelines: A review, J. Nat. Gas Sci. Eng. 32, 364.

2 Pack D.J., Parks D.W., Chesnoy A.B. (2012) Gas pipeline preferential site selection occurrence for elemental sulphur \& other particle matter formation \& deposition, J. Pet. Sci. Eng. 94-95, 12.

3 Edlund D.J., Pledger W.A. (1993) Thermolysis of hydrogen sulfide in a metal-membrane reactor, J. Memb. Sci. 77, 255.

4 Syed M., Soreanu G., Falletta P., Béland M. (2006) Removal of hydrogen sulfide from gas streams using biological processes - A review, Can. Biosyst. Eng. 48, 2.

5 Eow J.S. (2002) Recovery of sulfur from sour acid gas: A review of the technology, Environ. Prog. 21, 143.

6 Benge G., Dew E.G. (2005) Meeting the challenges in design and execution of two high rate acid gas injection wells, in: SPE/IADC Drilling Conference, 23-25 February, Amsterdam, Netherlands, 6 p.

7 Li Q., Liu X., Du L., Bai B., Fang Z., Jing M., Li X. (2013) Economics of acid gas injection with comparison to sulfur recovery in China, Energy Procedia 37, 2505.

8 El-Bishtawi R., Haimour N. (2004) Claus recycle with double combustion process, Fuel Process. Technol. 86, 245. 
9 Pietro Reverberi A., Klemeš J.J., Varbanov P.S., Fabiano B. (2016) A review on hydrogen production from hydrogen sulphide by chemical and photochemical methods, J. Clean. Prod. 136, 72 .

10 Adewale R.A., Berrouk A.S., Dara S. (2015) A process simulation study of hydrogen and sulfur production from hydrogen sulfide using the $\mathrm{Fe}-\mathrm{Cl}$ hybrid process, J. Taiwan Inst. Chem. Eng. 54, 20.

11 Huang H., Yu Y., Chung K.H. (2009) Recovery of hydrogen and sulfur by indirect electrolysis of hydrogen sulfide, Energy Fuels 23, 4420.

12 Adewale R., Salem D.J., Berrouk A.S., Dara S. (2016) Simulation of hydrogen production from thermal decomposition of hydrogen sulfide in sulfur recovery units, J. Clean. Prod. 112, 4815.

13 Huisman H.M., van der Berg P., Mos R., van Dillen A.J., Geus J.W. (1994) Hydrolysis of carbon sulfides on titania and alumina catalysts; the influence of water, Appl. Catal. A Gen. 115, 157.

14 Damanabi A.T., Bahadori F. (2019) A new approach for hydrogen production in Claus sulfur recovery process, $J$. Sulfur Chem. 40, 137.

15 ZareNezhad B. (2009) An investigation on the most important influencing parameters regarding the selection of the proper catalysts for Claus SRU converters, J. Ind. Eng. Chem. 15, 143.

16 Signor S., Manenti F., Grottoli M.G., Fabbri P., Pierucci S. (2010) Sulfur recovery units: Adaptive simulation and model validation on an industrial plant, Ind. Eng. Chem. Res. 49, 5714

17 Lins V.F.C., Guimarães E.M. (2007) Failure of a heat exchanger generated by an excess of $\mathrm{SO}_{2}$ and $\mathrm{H}_{2} \mathrm{~S}$ in the sulfur recovery unit of a petroleum refinery, J. Loss Prev. Process Ind. 20, 91.

18 ZareNezhad B., Hosseinpour N. (2008) Evaluation of different alternatives for increasing the reaction furnace temperature of Claus SRU by chemical equilibrium calculations, Appl. Therm. Eng. 28, 738.

19 Boussetta N., Lanoisellé J.-L., Bedel-Cloutour C., Vorobiev E. (2009) Extraction of soluble matter from grape pomace by high voltage electrical discharges for polyphenol recovery: Effect of sulphur dioxide and thermal treatments, J. Food Eng. 95, 192.
20 Gens T.A. (1994) Decrease in carbonyl sulfide in the feed to Claus converters by shift catalysts, Ind. Eng. Chem. Res. 33, 1654 .

21 Chardonneaua M., Ibrahim S., Gupta A.K., AlShoaibi A. (2015) Role of toluene and carbon dioxide on sulfur recovery efficiency in a Claus process, Energy Procedia 75, 3071.

22 Ibrahim S., Al Shoaibi A., Gupta A.K. (2014) Toluene destruction in thermal stage of Claus reactor with oxygen enriched air, Appl. Energy 115, 1.

23 Ibrahim S., Rahman R.K., Raj A. (2017) Effects of $\mathrm{H}_{2} \mathrm{O}$ in the feed of sulfur recovery unit on sulfur production and aromatics emission from Claus furnace, Ind. Eng. Chem. Res. 56, 11713.

24 Craig B.D., Anderson D.S. (1995) Handbook of corrosion data, ASM International, Materials Park, OH.

25 Rahman R.K., Ibrahim S., Raj A. (2016) Oxidative destruction of monocyclic and polycyclic aromatic hydrocarbon (PAH) contaminants in sulfur recovery units, Chem. Eng. Sci. 155, 348.

26 Zarei S., Ganji H., Sadi M., Rashidzadeh M. (2016) Thermokinetic modeling and optimization of the sulfur recovery unit thermal stage, Appl. Therm. Eng. 103, 1095.

27 Asadi S., Pakizeh M., Pourafshari Chenar M. (2011) An investigation of reaction furnace temperatures and sulfur recovery, Front. Chem. Sci. Eng. 5, 362.

28 Zagoruiko A.N., Matros Y.S. (2002) Mathematical modelling of Claus reactors undergoing sulfur condensation and evaporation, Chem. Eng. J. 87, 73.

29 Clarke D.S., Iyengar J.M., Alkhaldy M., Summers S. (2001) Qatar gas sulfur recovery improvement project, in: Proceedings of the Laurance Reid Gas Conditioning Conference, pp. 85-104.

30 Mattsson-Bose K.W., Lyddon L.G. (1997) Using a process simulator to improve sulphur recovery, in: SULPHURLONDON-, British Sulphur Publishing, $37 \mathrm{p}$.

31 Monnery W.D., Svrcek W.Y., Behie L.A. (1993) Modelling the modified claus process reaction furnace and the implications on plant design and recovery, Can. J. Chem. Eng. 71, 711.

32 Selim H., Ibrahim S., Al Shoaibi A., Gupta A.K. (2013) Effect of oxygen enrichment on acid gas combustion in hydrogen/air flames under Claus conditions, Appl. Energy 109, 119.

33 Bohme G., Sames J.A. (1999) The seven deadly sins of sulphur recovery, in: International Sulphur'99 Conference, Memorias Sulphur Experts Inc., Calgary, AB, Canada, 1999 p. 